\title{
African swine fever virus - persistence in different environmental conditions and the possibility of its indirect transmission
}

\author{
Natalia Mazur-Panasiuk, Jacek Żmudzki, Grzegorz Woźniakowski \\ Department of Swine Diseases, \\ National Veterinary Research Institute, 24-100 Puławy, Poland \\ natalia.mazur@piwet.pulawy.pl
}

Received: April 25, 2019

Accepted: August 12, 2019

\begin{abstract}
Since 2007, African swine fever (ASF) has posed a serious threat to the European swine industry. In Poland, the numbers of reported outbreaks in pigs and affected areas grow every year. In 2018, the disease was noted in Western Europe, in Belgium specifically, where several hundred infected wild boars have been detected so far. In 2018, the virus unexpectedly emerged in pig holdings in eastern China, northern Mongolia, Vietnam, and Cambodia, causing worldwide concern about its further spread. Since there is still no vaccine available, the only approach to control the disease is biosecurity. Identification of potential sources of the virus is extremely important in light of its phenomenal survivability. The review summarises the current knowledge about ASFV survivability and resistance to environmental conditions, and discusses the role of indirect contact in spreading the disease.
\end{abstract}

Keywords: ASFV, stability, survivability, indirect transmission, spreading.

\section{Introduction}

African swine fever (ASF) is an infectious disease causing high mortality of pigs, and is notifiable to the World Organisation of Animal Health (OIE). The aetiological agent, African swine fever virus (ASFV), is classified as the sole member of the Asfarviridae family and is among the large $(200 \mathrm{~nm})$, complex, enveloped double-stranded DNA viruses (11). ASFV affects domestic and wild members of the Suidae family, leading to a wide range of symptoms from chronic or persistent infection to acute haemorrhagic fever, and inflicts up to $100 \%$ mortality (18). The main routes for disease transmission are direct contact between susceptible and sick animals or their fluids or excretions, and indirect contact through contaminated feed, pork meat, people, vehicles, or fomites $(10,13$, 31). In endemic areas, ASFV also infects soft ticks of the Ornithodoros genus, making them actively engaged in the disease epidemiology due to their potential to indirectly transmit the virus to susceptible vertebrate hosts (43). Studies regarding hard ticks (Ixodes ricinus and Dermacentor reticulatus) as a source of ASFV demonstrated that these parasites facilitate neither virus replication nor tick-to-pig transmission, at least under laboratory conditions; nevertheless, viral DNA can persist in the tick organism up to eight weeks, allowing them to act as mechanical vectors (8). Mellor et al. (29) proved that the stable fly, Stomoxys calcitrans, is able to mechanically transmit the virus up to $24 \mathrm{~h}$ post digestion of ASFV infected blood. Moreover, a recent study conducted by Olesen et al. (39) established that infection of pigs might also occur following the oral uptake of flies fed ASFV-infected blood.

ASFV resistance and stability have attracted the interest of numerous investigators over the years $(5,7$, $10,23,26-28,41,42,47)$. It has been proved that ASFV shows high resistance to environmental conditions and remains infectious over a long storage time either below $0^{\circ} \mathrm{C}$ or at $4^{\circ} \mathrm{C}$. The curing process of infected meat (a process like that which Parma, Iberian, or Serrano ham undergoes) facilitated survival of ASFV in ham for over a year (28). ASFV can survive many freeze-thaw cycles, and furthermore it is stable at $\mathrm{pH}$ levels between 4 and 13 and can survive a temperature of $56^{\circ} \mathrm{C}$ for over an hour (42). 
Due to its high stability, ASFV is able to persist for a long time in contaminated fomites or meat; therefore they could play a role as vehicles for the transboundary or even transcontinental spread of the pathogen. Such a mode of dissemination is one of the most frequent routes of ASFV introduction into territories previously free of it. For example, in 2007 an ASF outbreak in Georgia was caused by improper disposal of contaminated pork meat from a ship at Poti docks. Similar events occurred in history to cause other ASFV introductions, namely to Portugal (1957), Cuba (1971), Brazil (1978), and Belgium (1985) (10, 31). Besides through the negligence by which humans spread the disease transnationally, ASFV is present in an environment because of its long persistence in wild boar carcasses, which can in effect be a virus reservoir. Therefore eradication of the disease is extremely difficult, due to the necessity of actively searching for decaying boar cadavers to make possible the proper disposal of infected carcasses (3).

\section{ASFV resistance to physical treatment}

Over a span of many years, numerous experiments were dedicated to ASFV stability. As far back as 1921, Montgomery (30) demonstrated that ASFV is extremely resistant to high temperatures, putrefaction and desiccation. Much later, Coggins (5) evidenced high ASFV resistance to selected chemical (trypsin and EDTA) and physical treatments (freezing/thawing and ultrasonic waves). In the same study he successfully collected viable virus after $1 \mathrm{~h}$ incubation at $56^{\circ} \mathrm{C}$ and one week at $37^{\circ} \mathrm{C}$. Plowright and Parker (42) in 1967 showed that storing at $4^{\circ} \mathrm{C}$ preserves infectivity of viraemic blood for at least 75 weeks and of virusspiked medium without $\mathrm{Ca}^{2+}$ or $\mathrm{Mg}^{2+}$ for 61 weeks. At $37^{\circ} \mathrm{C}$, medium containing ASFV remained infectious for $11-22$ days, but at $60^{\circ} \mathrm{C}$ it was only for $30 \mathrm{~min}$. It was also shown that the virus is stable over a wide $\mathrm{pH}$ range (from $\mathrm{pH} 3.9$ to 13.4) for seven days (in serum-supplemented media) (42). Another study concerning ASFV resistance to temperature was conducted more recently, and partially confirmed previous results. It was shown that the virus was stable at 4,22 , and $40^{\circ} \mathrm{C}$ and lost only less than $10^{1} 50 \%$ haemadsorption doses $\left(\mathrm{HAD}_{50}\right) / \mathrm{mL}$ during $24 \mathrm{~h}$ incubation in EMEM. At $50^{\circ} \mathrm{C}$, only a small fraction of virus remained infectious, and at $60^{\circ} \mathrm{C}$ no infectious virions could be detected after only $15 \mathrm{~min}$ (47). In summary, ASFV in tissues can survive deep freezing $\left(-70^{\circ} \mathrm{C}\right)$ for many years without significant loss of titre, but at $-20^{\circ} \mathrm{C}$ it systematically loses its titre, nevertheless remaining viable for at least 105 weeks (2 years) (42). At $4^{\circ} \mathrm{C}$ it is also very stable when contained in medium; it remains infectious for at least 61 weeks (1 year and 2 months). In higher temperatures $\mathrm{ASFV}$ is inactivated relatively quickly. At $37^{\circ} \mathrm{C}$ traces of viable virus could be found after 22 days, at $56^{\circ} \mathrm{C}$ after $1 \mathrm{~h}$, but at $60^{\circ} \mathrm{C}$ no longer than after $15 \mathrm{~min}$.

\section{Direct transmission}

Direct contact between sick and susceptible animals has repeatedly been proved to be an effective transmission route for ASFV $(2,14,17,21,38,41,48)$. Recent experiments conducted with current ASFV European strains showed that viral DNA and/or infective virus might be detected in blood (first detection at $3.75 \pm 1.4 \mathrm{dpi})(2,14,17,21,33,38,41$, 48), nasal, rectal, and oral fluids $(21,33,37,41,48)$, and faeces and urine $(7,21,37,38)$ of infected animals. The highest viral loads in blood are recorded between 5 and 27 dpi by intramuscular or intranasal inoculation or 9 and 29 dpi when pig-to-pig contact is investigated, and maximum ASFV titres in blood range from $10^{6}$ to $10^{9} \mathrm{HAD}_{50} / \mathrm{mL}$ in the acute phase (Table 1 ).

As regards excretions and secretions, it has been demonstrated that they might contain viable virus (1.6-4.8 $\log _{10} \mathrm{HAD}_{50} / \mathrm{mL}$ ) (Table 1) on the day of euthanasia, but in the case of contact animals, the virus was molecularly detected in nasal fluid prior to being evident in blood (38). ASFV survivability in these contaminated excretions depends mainly on temperature; however, in favourable conditions it may retain its viability for long time, increasing the risk of the disease spreading, particularly under lowbiosecurity conditions (13).

It has been clearly and repeatedly shown, that solely air contact (without direct physical contact between sick and healthy animals) is sufficient to develop a clinical course of the disease in susceptible pigs $(9,38,50)$. Air sampled during experimental infection was consistently molecularly and virologically positive during the first 25-30 days after infection, with virus titres up to $10^{3.2}$ TCID $_{50}$ eq. $/ \mathrm{m}^{3}(9)$.

\section{ASFV survival in excretions}

As the viable virus has been identified in excretions, it raises the question of how long the virus can survive in them. Montgomery (30) showed as long ago as 1921 that when faeces are stored in the dark at room temperature they remain infective for at least 11 days, but other later studies showed that this time might be extended up to 160 days (13). The most recent investigations indicated that ASFV stability in faeces is much lower than previously thought and depends largely on the temperature. Faeces collected from experimentally inoculated pigs remained infectious for 8 days at $4^{\circ} \mathrm{C}$, and for $3-4$ days at $37^{\circ} \mathrm{C}$. When it comes to urine, it might contain viable virus for up to 15 days at $4^{\circ} \mathrm{C}, 5$ days at $21^{\circ} \mathrm{C}$, and $2-3$ days at $37^{\circ} \mathrm{C}(7)$. 
Table 1. Current Eurasian ASFV strain levels of maximum viraemia in blood and shedding potential in other body fluids after various modes of inoculation

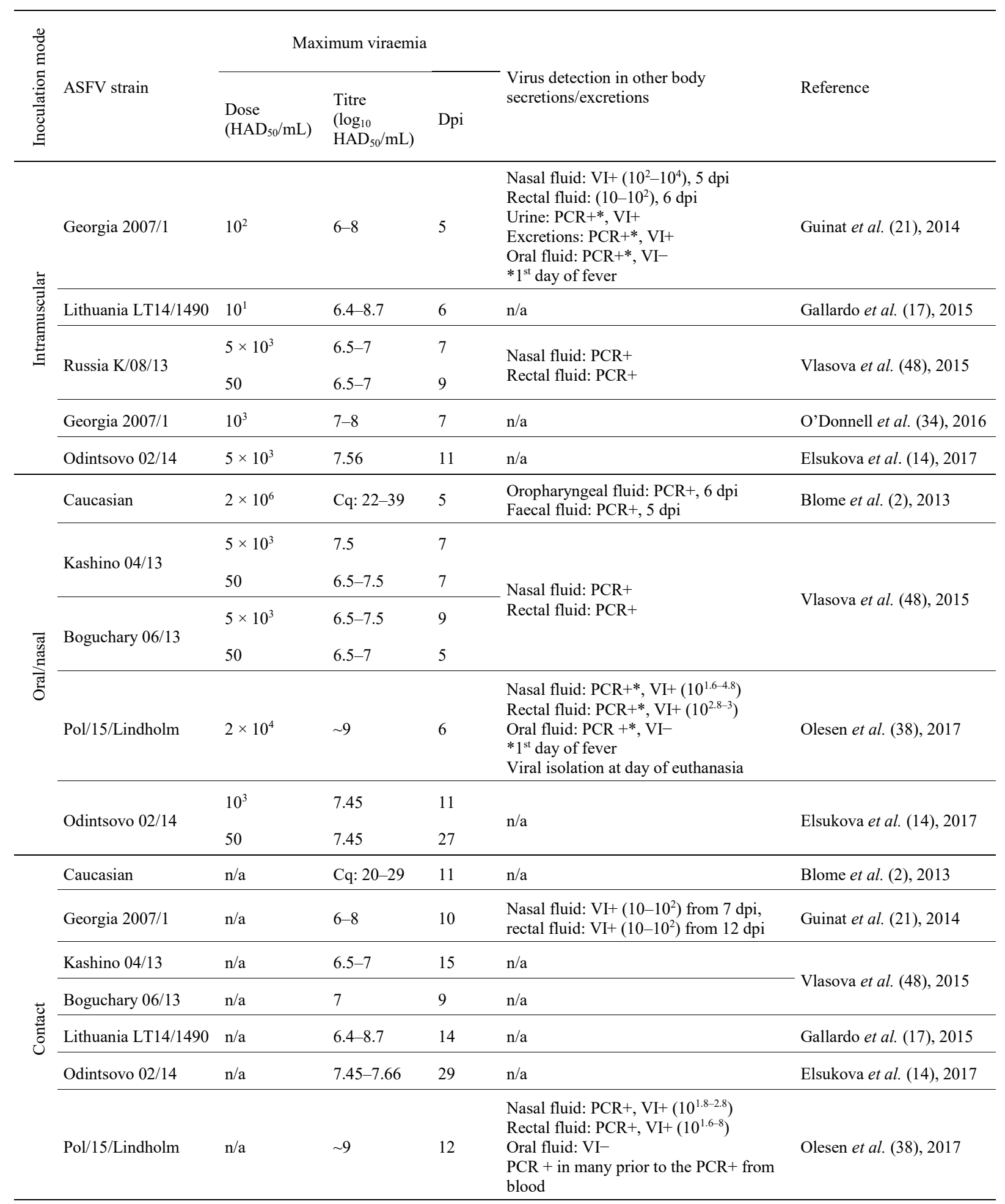

n/a - not applicable, dpi - day post infection, $\mathrm{HAD}_{50} / \mathrm{mL}$ - haemadsorbing doses per millilitre, $\mathrm{PCR}+(-)-$ viral DNA detected (not detected) by real-time PCR, $\mathrm{VI}+(-)$ - infectious virus detected (not detected) by virus isolation in cell culture

The study by Olesen et al. (37) conducted in vivo, was in line with these results and showed that the time span required for inactivation of ASFV in excretions is relatively short: pigs introduced into pens contaminated with faeces and urine one day after the removal of infected pigs succumbed to experimental ASFV infection, although they were not susceptible to infection after three days. However, for the first time it was demonstrated experimentally that exposure of pigs to an environment contaminated with virus-containing excretions might result in infection. Excretions containing viable ASFV should be considered 
an important route for virus transmission, particularly within a herd. Moreover, as the infective dose of ASFV is small - estimated at $10^{1} \mathrm{HAD}_{50} / \mathrm{mL}$ via oronasal inoculation - a small amount of infective virus included in excretions might contaminate some fomites like clothes, footwear, equipment, etc. In consequence of this, the probability of virus transmission to other pens or even farms cannot be ruled out.

\section{Indirect contact - contaminated fomites, feed, and drinking water}

Since infectious ASFV is secreted and excreted, it therefore easily contaminates the environment, which subsequently may act as a virus source. Numerous epidemiological studies have proved that ASFV can be easily transmitted, either by direct contact or indirectly, via swill feed or contaminated fomites like clothes, footwear, equipment, food waste, bedding, etc. The most spectacular example of the disease spreading through fomites is its current epidemics in Europe, where it was introduced by ships containing ASFVcontaminated kitchen wastes used to feed pigs near Poti docks. Subsequently, the disease spread quickly to the neighbouring Caucasian region, then to Eastern Europe, and finally reached European Union countries in 2014 (4). Presently, as a result of that single introduction into Georgia, the disease is prevalent in 13 European countries (excluding Italy, where the disease has a different origin, and the Czech Republic, which has already eradicated the disease) and poses a serious threat to the pig industry of the remaining ones.

In 2018, ASF unexpectedly emerged in eastern Asia where dozens of outbreaks in pigs were reported in China and Mongolia, and in 2019 ASF struck also in Vietnam (35). Molecular characterisation of the intergenic region (IGR) between the I73R and I329L genes revealed a high level of DNA sequence similarity between recent Chinese and Eastern European (IGR II) ASFV isolates, but not between Chinese and Siberian ones (of the Irkutsk 2017 strain) (IGR I) (19, 22, 25). The exact origin of the disease in eastern Asia still remains unknown and needs further investigation; nevertheless a recent phylogenetic analysis indicated that ASFV in China might have had at least two independent introductions due to some level of divergence in nucleotide sequences obtained from cases which occurred far from each other (49). Most of the outbreaks which recently emerged in China were separated by thousands of kilometres, suggesting that the spread of the disease might be associated with contaminated feed. This hypothesis seems to be probable, in particular having regard to the fact that ASFV DNA has been detected in pig feed and feed ingredients like dried pig blood $(24,44,49)$. In Europe, besides on backyard farms, the disease has been reported on numerous high-biosecurity operations (12). In Romania, ASFV was introduced into a high biosecurity breeding farm containing up to 140,000 pigs; however, the exact source of the disease has not been determined. Hypothetically it may have originated from contaminated water in the nearby Danube River (3).

Several experimental studies have demonstrated that transmission via contaminated feed is possible; nonetheless the knowledge is relatively poor concerning fomite-to-pig transmission $(6,10,20,32)$. In 1969 Colgrove et al. (6) effectively infected pigs orally through solid feed contaminated with minced tissues from sick animals. Shortly thereafter it was proved that when consumed by a susceptible pig, ASFV contained in milk led to infection, but it required a relatively high virus load of $10^{5.4} \mathrm{HAD}_{50} / \mathrm{mL}$ (20). An in vitro study published in 2018 demonstrated that artificially ASFV-contaminated feed ingredients had viable virus pathogens for at least 30 days (10). The most recent study conducted by Niederwerder et al. (32) determined the minimum infectious dose of ASFV through natural oral exposure via drinking and feeding behaviours. The investigation showed that as little as $10^{0} \mathrm{TCID}_{50}$ contained in liquid is required to develop successful infection, whereas a dose of $10^{4} \mathrm{TCID}_{50}$ is needed in solid, plant-based feed (32). Moreover, the study demonstrated that a liquid diet has a much higher infection probability compared with dried feed. The highest dose tested in liquid $\left(10^{4}\right)$ led to infection of $100 \%$ of experimental pigs, while neither of the investigated solid feed doses showed such a high rate of infection (32). Furthermore, the study published by Sindryakova et al. (46) in 2016 showed that feed and water contaminated by infectious blood stored at $4{ }^{\circ} \mathrm{C}$ preserved ASFV viability for 30 and at least 60 days (the duration of the whole study), respectively. On the other hand, storage at room temperature resulted in far shorter ASFV survival: in feed to 1 day and in water to 50 days. Therefore, contaminated feed and water stored at $4{ }^{\circ} \mathrm{C}$ might pose a risk of infection over at least 30-day and 60-day periods, respectively (46).

Accordingly to these experimental data and recent epidemiological findings in Europe and Asia, long-distance (transboundary and transcontinental) movement of ASFV with contaminated feed and feed ingredients should be considered a possible mode of virus spread, especially within ASF-free areas.

\section{ASFV survival in raw meat and offal}

Historically, ASFV introduction into distant disease-free territories has been attributed to the consumption of contaminated pork or pork products $(31,45)$. Moreover, although prohibited in the EU and in contravention of biosecurity measures, swill feeding is still a common practice all over the world, especially in free-ranging and backyard farms (1). Therefore, contaminated pork presents a possible mode of transmission for ASFV. Heated, cooked, and canned 
meat products are generally considered safe as regards any viable pathogen presence, which has been experimentally demonstrated $(5,42,46)$. Several experiments provided data concerning ASFV stability in raw and processed meat and other pork products (13, 26). Frozen raw meat and organs provide ASFV viability for periods lasting from 103 to 118 days, but according to Adkin et al. (13) ASFV may remain infectious for even up to 1,000 days. In meat stored at $4-8^{\circ} \mathrm{C}$, a viable virus could be detected over 84 - to 155-day periods (13). Infected spleen samples stored in a refrigerator remained infectious for 204 days, but when buried in soil in June at $8 \mathrm{~cm}$ depth it remained so for 280 days. Bone marrow (in boned meat) remained infectious for 180-188 days, skin and fat for 300 days, and offal for 105 days, however the temperature at which these samples were stored was not stated despite its being a key factor for virus survivability (13).

\section{ASFV survival in dry-cured pork}

The matter of ASFV survival in products which cannot be heat-treated but are preserved through salting and drying is more complicated than in raw pork (12). The studies regarding ASFV survival in dry-cured processed meat are limited to ham, Spanish and Italian shoulder, loin, smoked pepperoni and salami, pork belly, and corned meat $(26-28,40,46)$. Salami and pepperoni might remain infectious up to 30 days (26). Pork belly and loin were demonstrated to still contain viable ASFV after 60 and 83 days, which is longer than the duration of their commercial curing processes (14-21 and 60 days, respectively) but still within the shelf-life of the products. These pork products pose a low potential short-term risk if in swill fed to pigs (40). Corned meat stored at $4-6^{\circ} \mathrm{C}$ remained infectious for at least 60 days (the study duration), nevertheless the time reduced to 16 days as the temperature increased to room temperature (42). Ripening hams, like Iberian loin (112 days), shoulders (140 days), and Serrano and Parma (respectively 180 and 300-399 days) hams might remain infectious relatively long, but still cease to be within the duration of the curing process, which lasts much longer (13, 27, 28). Therefore the curing time is sufficient to inactivate ASFV and these products should be considered safe.

\section{Indirect contact - arthropods as mechanical vectors}

ASFV is a tick-borne virus; therefore ticks as well as pigs may host the virus. Nevertheless, so far only soft ticks of Ornithodoros spp. have been found to facilitate virus replication, and they act as the main virus reservoirs in Africa where they participate in the so-called sylvatic ASFV transmission cycle between ticks and wild suids. The geographical distribution of these ticks is limited to Africa and southern Europe
(Mediterranean countries). Other ticks belonging to the Ixodes ricinus and Dermacentor reticulatus species are particularly present in Central Europe and represent a major group of mammalian parasites within this climate zone $(8,16)$.

Nevertheless, as several cases of ASFV outbreaks have been reported on high-biosecurity farms in Eastern Europe and the Baltic States where the density of infected wild boars was high, the question arises whether arthropods may play a mechanical vector role between wild and domestic pigs. Hard ticks were investigated to determine their competence as an ASFV vector. ASFV was not detected either in the fieldcollected ticks or ticks fed infectious blood which transmitted the virus to susceptible animals in laboratory conditions (8). ASF virus does not replicate within the tick organisms; however, viral DNA could be detected from six to eight weeks after feeding with infected blood. Therefore, hard ticks may represent only a potential mechanical but not a biological vector in transmission between wild boars and pigs (8).

The stable fly, Stomoxys calcitrans, is able to mechanically transmit the virus for $24 \mathrm{~h}$ post contact with infected blood, but only by the ingestion route. Moreover, infectious virus survived in these flies for at least two days (29). Olesen et al. (36) demonstrated that viable ASFV is present in the bodies of flies fed infectious blood for up to $12 \mathrm{~h}$ and DNA could be detected there for three days post feeding. These results indicate that such flies might mechanically transmit the virus to susceptible hosts. The dose contained in only one fly, when ingested, was sufficient to develop clinical signs of the disease in a pig. Nevertheless, spatial separation is likely to constrain the stable fly vector, and transmission within a herd is considered to be more probable than transmission between farms. Therefore, occurrence of indirect transmission of the virus within distant farms via ASFV-contaminated flies remains virtually impossible $(39,36)$. Another study verified the hypothesis whether fly larvae growing in and feeding on carcasses of infected wild boars might be involved in disease spreading. However, despite ASFV DNA presence, it was demonstrated that virus replication within larvae is absent. It was stated that although feeding by wild boars on larvae-ridden carrion was highly improbable, it could not be ruled out, although the researchers contended that blowfly larvae do not play a significant role in ASFV spreading via mechanical transmission (15).

Adducing evidence from fieldwork, viral DNA was detected in Poland in stable flies collected from farms during disease outbreaks in pigs as well as in hard ticks (Dermacentor reticulatus and Ixodes ricinus) collected from the bodies of dead ASFV-positive wild boars (Woźniakowski 2019, unpublished data). This suggests that arthropods cannot be excluded as ASFV mechanical transmission factors; nevertheless this issue needs further investigation. 


\section{Conclusions and future research perspectives}

Along with increasing globalisation, the introduction of human and animal diseases is going to pose a continuous threat to public and livestock health, trade of animals and their products, and food security. Worldwide, the pig-farming industry is constantly growing in reply to rising demand for pork meat. Nevertheless, this branch of the economy is particularly vulnerable to production decimation because of transmission of various transboundary infectious diseases, amongst which ASF is currently causing the greatest concern. During recent years, ASFV has been spreading towards new areas; however, the most dramatic turn occurred in 2018, when the disease emerged in China, the top pig-farming nation providing half of global pig production. Due to the lack of a safe effective vaccine and the common presence of infected wild boars in particular areas, the only method to control the disease is strict biosecurity measures allied to international cooperation on this matter. Knowledge and epidemiological understanding of how the virus may be introduced into susceptible populations of pigs is crucial to provide awareness to prevent the outbreaks and detect and control them immediately and appropriately when they do occur. Therefore, identification of potential sources and pathways of transmission in regards to ASFV is exceptionally important to prevent further disease spread.

ASFV stability in different environmental conditions was the subject of numerous investigations, but most of them were conducted in the previous century. The virus has been identified as extremely resistant to physical treatment such as high temperatures, putrefaction and desiccation, freezing/thawing, ultrasonic waves, or extreme $\mathrm{pH}$ values. Low temperatures, such as the $-20^{\circ} \mathrm{C}$ usually required to preserve pork meat, facilitate virus survival for years. Raw meat and other pork products can provide long ASFV survivability, but the temperature conditions are the main factor directly influencing virus stability. Ripening hams and dry-cured meat products may contain viable virus, nevertheless it depends greatly on the preparation and conservation techniques, which differ widely between regions and countries.

In reference to the disease's transmission, it was proved that ASFV infectivity without a susceptible animal having direct contact with infected blood is rather moderate; nevertheless, transmission only via air contact is still possible. Moreover, excretions and secretions are also considered infectious and they may participate in disease spread. Indirect transmission of ASFV by contaminated feed products has been shown to be possible for at least 30 days. Moreover, it was proved that oral uptake of contaminated liquid will more likely lead to infection than uptake of contaminated solid feed. A $10^{0} \mathrm{HAD}_{50} / \mathrm{mL}$ dose received with liquid is sufficient to induce clinical signs of the disease. Despite scrutiny of the preventive measures which were undertaken, the source of the disease's introduction onto farms has remained unknown in the majority of ASFV outbreaks recently reported in Central Europe. It is suggested that arthropods like flies or ticks may act as mechanical vectors. Laboratory investigations partially confirmed this hypothesis, but infection was possible only via ingestion of flies no longer than $24 \mathrm{~h}$ after the insects has been fed infected blood. Therefore, while involvement of such arthropods in disease spread seems to be strictly limited, it cannot be ruled out.

As regards ASFV survivability and its indirect transmission, there are still data that are missing, e.g. those to result from investigation of the mechanism explaining outbreaks on high-biosecurity farms located near areas where infected wild boars are present but direct contact between them and domestic pigs is not possible. Further studies concerning arthropods' competence to become a mechanical vector for ASFV spread are needed. ASFV susceptibility to various environmental conditions is well studied; nevertheless there is still a lack of knowledge regarding the possibility of virus transmission on the surfaces of certain fomites, e.g. fresh grass contaminated with viable ASFV originating from wild boars, which could also elucidate the source of disease at least on part of the farms of Central Europe.

Conflict of Interests Statement: The authors declare that there is no conflict of interests regarding the publication of this article.

Financial Disclosure Statement: The study was supported by the National Science Centre (grant number UMO-2016/21/D/NZ6/00974) and the KNOW (Leading National Research Centre) Scientific Consortium "Healthy Animal - Safe Food" under decision of the Ministry of Science and Higher Education number 05-1/KNOW2/2015.

Animal Rights Statement: Not applicable.

\section{References}

1. Bellini S., Rutili D., Guberti V.: Preventive measures aimed at minimizing the risk of African swine fever virus spread in pig farming systems. Acta Vet Scand 2016, 58, article 82

2. Blome S., Gabriel C., Beer M.: Pathogenesis of African swine fever in domestic pigs and European wild boar. Virus Res 2013, $173,122-130$

3. Boklund A., Cay B., Depner K., Zsolt F., Guberti V., Masiulis M., Spiridon M., Ståhl K., Miteva A., More S., Olsevskis E., Satr P., Thulke H., Viltrop A., Wozniakowski G., Broglia A., Abrahantes C., Gogin A., Verdonck F., Amato L.: Epidemiological analyses of African swine fever in the European Union (November 2017 until November 2018). EFSA J 2018, 16, 54942018. doi: 10.2903/j.efsa.2018.5494.

4. Chenais E., Depner K., Guberti V., Dietze K., Viltrop A., Ståhl K.: Epidemiological considerations on African swine fever in Europe 2014-2018. Porc Heal Manag 2019, 5, 1-10. 
5. Coggins L.: Growth and certain stability of African swine fever virus. Am J Vet Res 1966, 27, 1351-1358.

6. Colgrove G.S., Haelterman E.O., Coggins L.: Pathogenesis of African swine fever in young pigs. Am J Vet Res 1969, 30, 1343-1359.

7. Davies K., Goatley L.C., Guinat C., Netherton C.L., Gubbins S., Dixon L.K., Reis A.L.: Survival of African swine fever virus in excretions from pigs experimentally infected with the Georgia 2007/1 isolate. Transbound Emerg Dis 2015, 64, 425-431.

8. De Carvalho Ferreira H.C., Tudela Zúquete S., Wijnveld M., Weesendorp E., Jongejan F., Stegeman A., Loeffen W.L.A.: No evidence of African swine fever virus replication in hard ticks. Ticks Tick Borne Dis 2014, 5, 582-589.

9. De Carvalho Ferreira H.C., Weesendorp E., Quak S., Stegeman J.A., Loeffen W.L.A.: Quantification of airborne African swine fever virus after experimental infection. Vet Microbiol 2013, 165, 243-251.

10. Dee S.A., Bauermann F.V., Niederwerder M.C., Singrey A., Clement T., de Lima M., Long C., Patterson G., Sheahan M.A., Stoian A.M.M., Petrovan V., Jones C.K., De Jong J., Ji J., Spronk G.D., Minion L., Christopher-Hennings J., Zimmerman J.J., Rowland R.R.R., Nelson E., Sundberg P., Diel D.G.: Survival of viral pathogens in animal feed ingredients under transboundary shipping models. PLoS ONE 2018, 13(3): e0194509, doi: 10.1371/journal.pone.0194509.

11. Dixon L.K., Chapman D.A.G., Netherton C.L., Upton C.: African swine fever virus replication and genomics. Virus Res 2013, 173, 3-14.

12. EFSA AHAW Panel: African swine fever. EFSA J 2015, 13, 4163.

13. EFSA AHAW Panel: Scientific opinion on African swine fever. EFSA J 2014, 12, 3628.

14. Elsukova A., Shevchenko I., Varentsova A., Puzankova O.: Biological properties of African swine fever virus Odintsovo 02/14 isolate and its genome analysis. Int J Environ Agric Res 2017, 3, 26-37.

15. Forth J.H., Amendt J., Blome S., Depner K., Kampen H.: Evaluation of blowfly larvae (Diptera: Calliphoridae) as possible reservoirs and mechanical vectors of African swine fever virus. Transbound Emerg Dis 2018, 65, e210-e213. doi: $10.1111 /$ tbed. 12688 .

16. Frant M., Woźniakowski G., Pejsak Z.: African swine fever (ASF) and ticks. No risk of tick-mediated ASF spread in Poland and Baltic states. J Vet Res 2017, 61, 375-380.

17. Gallardo C., Soler A., Nieto R., Cano C., Pelayo V., Sanchez M.A., Pridotkas G., Fernandez-Pinero J., Briones V., Arias M.: Experimental infection of domestic pigs with African swine fever virus Lithuania 2014 Genotype II Field Isolate. Transbound Emerg Dis 2015, 64, 300-304.

18. Gallardo C., de la Torre Reoyo A., Fernández-Pinero J., Iglesias I., Muñoz M.J., Arias M.L.: African swine fever: a global view of the current challenge. Porc Heal Manag 2015, 1, article 21.

19. Ge S., Li J., Fan X., Liu F., Li L., Wang Q., Ren W., Bao J., Liu C., Wang H., Liu J., Zhang Y., Xu T., Wu X., Wang Z.: Molecular characterization of African swine fever virus, China, 2018. Emerg Infect Dis J 2018, 24, 2131-2133.

20. Greig A.: Pathogenesis of African swine fever in pigs naturally exposed to the disease. J Comp Pathol 1972, 82, 73-79.

21. Guinat C., Reis A.L., Netherton C.L., Goatley L., Pfeiffer D.U., Dixon L.: Dynamics of African swine fever virus shedding and excretion in domestic pigs infected by intramuscular inoculation and contact transmission. Vet Res 2014, 45, 1-9.

22. Imatdinov A.R., Malogolovkin A.S., Balyshev V.M., Vlasov M.E., Titov I.A., Morgunov S.Y.: Biological properties and molecular-genetic characteristics of African swine fever virus isolated in various regions of Russia in 2016-2017. Russ Agric Sci 2019, 44, 469-473.

23. Kalmar I.D., Cay A.B., Tignon M.: Sensitivity of African swine fever virus (ASFV) to heat, alkalinity and peroxide treatment in presence or absence of porcine plasma. Vet Microbiol 2018, 219, 144-149.
24. Kim H.J., Lee M.J., Lee S.K., Kim D., Seo S.J., Kang H.E., Nam H.M.: African swine fever virus in pork brought into South Korea by travelers from China, August 2018. Emerg Infect Dis J 2019, 25, 1231-1233.

25. Kolbasov D., Titov I., Tsybanov S., Gogin A., Malogolovkin A.: African swine fever virus, Siberia, Russia, 2017. Emerg Infect Dis J 2018, 24, 796-798.

26. McKercher P.D., Hess W.R., Hamdy F.: Residual viruses in pork products. Appl Environ Microbiol 1978, 35, 142-145.

27. Mebus C.A., House C., Gonzalvo F.R., Pineda J.M., Tapiador J., Pire J.J., Bergada J., Yedloutschnig R.J., Sahu S., Becerra V., Sánchez-Vizcaíno J.M.: Survival of foot-and-mouth disease, African swine fever, and hog cholera viruses in Spanish serrano cured hams and Iberian cured hams, shoulders and loins. Food Microbiol 1993, 10, 133-143.

28. Mebus C., Arias M., Pineda J.M., Tapiador J., House C., Sánchez-Vizcaíno J.M., Survival of several porcine viruses in different Spanish dry-cured meat products. Food Chem 1997, 59, 555-559.

29. Mellor P.S., Kitching R.P., Wilkinson P.J.: Mechanical transmission of capripox virus and African swine fever virus by Stomoxys calcitrans. Res Vet Sci 1987, 43, 109-112.

30. Montgomery E.R.: On a form of swine fever occurring in British East Africa (Kenya Colony). J Comp Pathol Ther 1921, 34, 159-191.

31. Mur L., Martínez-López B., Sánchez-Vizcaíno J.M.: Risk of African swine fever introduction into the European Union through transport-associated routes: returning trucks and waste from international ships and planes. BMC Vet Res 2012, 8, doi: 10.1186/1746-6148-8-149.

32. Niederwerder M.C., Stoian A.M.M., Rowland R.R.R., Dritz S.S., Petrovan V., Constance L.A., Gebhardt J.T., Olcha M., Jones C.K., Woodworth J.C., Fang Y., Liang J., Hefley T.J.: Infectious dose of African swine fever virus when consumed naturally in liquid or feed. Emerg Infect Dis 2019, 25, 891-897.

33. Nurmoja I., Petrov A., Breidenstein C., Zani L., Forth J.H., Beer M., Kristian M., Viltrop A., Blome S.: Biological characterization of African swine fever virus genotype II strains from north-eastern Estonia in European wild boar. Transbound Emerg Dis 2017, 64, 2034-2041.

34. O'Donnell V., Risatti G.R., Holinka L.G., Krug P., Carlson J., Velazquez-Salinas L., Azzinaro P.A., Gladue D.P., Borca M.V.: Simultaneous deletion of the $9 \mathrm{GL}$ and UK genes from the African swine fever virus Georgia 2007 isolate offers increased safety and protection against homologous challenge. J Virol 2016, 91, e01760-16. doi: 10.1128/JVI.01760-16.

35. OIE: OIE World Animal Health Information System http://www.oie.int/wahis_2/public/wahid.php/Reviewreport/Revi ew/viewsummary?reportid=29617.

36. Olesen A.S., Hansen M.F., Rasmussen T.B., Belsham G.J., Bødker R., Bøtner A.: Survival and localization of African swine fever virus in stable flies (Stomoxys calcitrans) after feeding on viremic blood using a membrane feeder. Vet Microbiol 2018, 222, 25-29.

37. Olesen A.S., Lohse L., Boklund A., Halasa T., Belsham G.J., Rasmussen T.B.: Short time window for transmissibility of African swine fever virus from a contaminated environment. Transbound Emerg Dis 2018, 65, 1024-1032.

38. Olesen A.S., Lohse L., Boklund A., Halasa T., Gallardo C., Pejsak Z., Belsham G.J., Rasmussen T.B., Bøtner A.: Transmission of African swine fever virus from infected pigs by direct contact and aerosol routes. Vet Microbiol 2017, 211, 92-102.

39. Olesen A.S., Lohse L., Frimodt Hansen M., Boklund A., Halasa T., Belsham G.J., Rasmussen T.B., Bøtner A., Bødker R.: Infection of pigs with African swine fever virus via ingestion of stable flies (Stomoxys calcitrans). Transbound Emerg Dis 2018, $65,1152-1157$

40. Petrini S., Feliziani F., Casciari C., Giammarioli M., Torresi C., De Mia G.M.: Survival of African swine fever virus (ASFV) in 
various traditional Italian dry-cured meat products. Prev Vet Med 2019, 162, 126-130.

41. Pietschmann J., Guinat C., Beer M., Pronin V., Tauscher K., Petrov A., Keil G., Blome S.: Course and transmission characteristics of oral low-dose infection of domestic pigs and European wild boar with a Caucasian African swine fever virus isolate. Arch Virol 2015, 160, 1657-1667.

42. Plowright W., Parker J.: The stability of African swine fever virus with particular reference to heat and $\mathrm{pH}$ inactivation. Arch Gesamte Virusforsch 1967, 21, 383-402.

43. Plowright W., Parker J., Peirce M.A.: African swine fever virus in ticks (Ornithodoros moubata, Murray) collected from animal burrows in Tanzania. Nature 1969, 221, 1071-1073.

44. Reuters: China finds African swine fever virus in some animal feed products. https://www.reuters.com/article/us-chinaswinefever/china-finds-african-swine-fever-virus-in-some-animalfeed-products-iduskcn1oo0fd.

45. Sánchez-Vizcaíno J.M., Mur L., Gomez-Villamandos J.C., Carrasco L.: An update on the epidemiology and pathology of African swine fever. J Comp Pathol 2015, 152, 9-21.

46. Sindryakova I.P., Morgunov Y.P., Chichikin A.Y., Gazaev I.K., Kudryashov D.A., Tsybanov S.Z.: The influence of temperature on the Russian isolate of African swine fever virus in pork products and feed with extrapolation to natural conditions. Sel'skokhozyaistvennaya Biol 2016, 51, 467-474.

47. Turner C., Williams S.M.: Laboratory-scale inactivation of African swine fever virus and swine vesicular disease virus in pig slurry. J Appl Microbiol 1999, 87, 148-157.

48. Vlasova N., Varentsova A., Shevchenko I., Zhukov I., Remyga S., Gavrilova V., Puzankova O., Shevtsov A., Zinyakov N., Gruzdev K.: Comparative analysis of clinical and biological characteristics of African swine fever virus isolates from 2013 year Russian Federation. Br Microbiol Res J 2015, 5, 203-215.

49. Wen X., He X., Zhang X., Zhang X., Liu L., Guan Y., Zhang Y.B.Z.: Genome sequences derived from pig and dried blood pig feed samples provide important insights into the transmission of African swine fever virus in China in 2018. Emerg Microbes Infect 2019, 8, 303-306.

50. Wilkinson P.J., Donaldson A.I., Greig A., Bruce W. Transmission studies with African swine fever virus: infections of pigs by airborne virus. J Comp Pathol 1977, 87, 487-495. 